Original Research Paper

\title{
Procedure of Implementation the Applied Orientation of Future Teachers' Training Using ICT
}

\author{
Indira Bakhytovna Usembayeva, Sherzod Jumadullaevich Ramankulov, Dinara Kadirkhankyzy Berdi, \\ Gulnar Amangeldievna Saparbekova and Bayan Saparbekovna Ualikhanova
}

H.A.Yassawe International Kazakh-Turkish University, Turkestan, SKR, The Republic of Kazakhstan, Kazakhstan

\author{
Article history \\ Received: 11-09-2015 \\ Revised: 20-09-2015 \\ Accepted: 22-09-2015 \\ Corresponding Author: \\ Indira Bakhytovna Usembayeva \\ H.A. Yassawe International \\ Kazakh-Turkish University, \\ Turkestan, SKR, the Republic \\ of Kazakhstan \\ Email: monblan.pro@yandex.ru, \\ indira.usembayeva@iktu.kz
}

\begin{abstract}
This research is aimed at the formation of applied orientation of future teachers' training using tools of Information and Communication Technology (ICT). To be successful in their career future teachers should have profound essential knowledge, put this knowledge to use, be well trained in general and major subjects and be able to improve their skills during their professional activity and to use up-to-date ICT tools. A methodological system was worked out during the research for this purpose. This methodological system has also undergone an experimental efficiency test. About 76 students from three different universities took part in the experiment. The results of the pedagogical experiment have verified our hypothesis that the offered procedure of educational process organization and implementation using ICT proves to be beneficial for improving quality of students' applicative knowledge and skills and increasing their interest in studying general and major subjects.
\end{abstract}

Keywords: Teaching Procedure, Applied Orientation, ICT Employment, Design Technology, Professional and Information Competence

\section{Introduction}

All human life constantly puts the demanding solutions before a person. Therefore, more and more deep knowledge of the world, opening of it all of new and new processes, properties and relationship of people and other objects is necessary (Thwaites et al., 2014). Students, as a rule, have no due idea of physical knowledge and skills application in future professional activity. The cognitive interest to studying of physics develops with the help of applied questions of physics that promotes formation of professional competence of future teachers.

Professional competence is the readiness and ability to act helpfully in accordance with the requirements of the case, methodically organized and independently solve problems and challenges, as well as independently assess the work results. In other words, it is the subject skills, appropriate methods and techniques inherent in the subjects.

The professional competence is considered as an integral characteristic of specialists' business and personal qualities, which reflects the level of knowledge, skills, experience sufficient to produce a certain kind of activity that is related to decision-making.
The professional competence of the future teachers is a multifactorial phenomenon including the teachers' theoretical knowledge system and methods of such knowledge application in specific teaching situations, the teachers' value orientation, as well as their culture integrative indicators (speech, communication styles, attitude to themselves and their activities, to the related fields of expertise).

Based on the analysis of research have been identified that professional competence includes a key, basic and special competence. All three types of competencies are interrelated. They form the individual style of pedagogical activity, create a complete image of a specialist and ultimately ensure the formation of his professional competence as a certain integrity as an integrative personality characteristics.

That's why forming of professional competence of the future teachers shall be made in such a logical sequence:

- The first stage is oriented on the forming of the key competences in context of the future professional activity

- During the second stage the learner is "immersed" in the professional cases, learns the methods of their solving. That facilitates the formation of the basic competence 
- The third stage is the formation of the specific competence

The basic competences must reflect the modern understanding of the main goals of professional activity and the key ones must reflect the ways of their solving. The specific competences realize the basic and the key ones according to the peculiarities of the professional pedagogical activity of a certain specialist.

In the key competences, we include the informational competence, which is based on the universal ability to work with different information sources and which envisages the pre-professional and social mobility of the person. The content of the universal skills, which belong to the information competence, varies according to the age peculiarities of the person and the circle of vital problems to be solved. Mastering of the information competence is connected, firstly with the extension of the information sources amount and secondly, it's connected with the extension of the amount of necessary skills.

Thus, the training of future chemistry teachers for ICT usage mitigates the formation of their key, basic and specific competences.

The main objective of higher educational institutions is high-quality training of the graduates as the prestige of higher education institution depends on it, its financing, number of the school students with good basic preparation choosing higher education institution, finally-development of the state and society. Therefore at any moments of the development society and the state sets rather actual tasks for the higher education-to make this education qualitative.

Reinforcement of the applied orientation of physics and the interrelation of its content and training procedures with practice is the primary renovating course of the modern education.

The problem of the applied orientation of physics courses is very important today. State of the art society is characterized by the rising role of physics and by application of the laws of physics to an investigation of the wide range of issues (Fishbane et al., 1996; DeWitt and Siraj, 2010). Physics became a tool for solving problems of industrial management and optimization, for studying of economic and social processes (Bodur, 2006). Employment of a computer favors the intensification of an educational process, the extension of the research field, the approaching of and educational activity to a professional one (Richards, 2004; Newhouse, 2003; Ghoorchian, 2003; Sousa, 2006).

Problems of didactics and methodology of employment of information and communication technologies in the educational process are studied in the works written by such scientists as (Toki and Pange, 2013; Judson, 2006; Larson, 2003; Khan, 2011; Berkimbaev et al., 2013).
Betcher and Lee (2009; Wieman et al., 2008; Steinberg et al., 1996) and other scientists have devoted their works to the problem of supplying the physics course with modern educational means in order to improve the teaching techniques. The issues of shaping the methodological and applicative knowledge of students studying physics and especially the section "Electricity and Magnetism" are poorly analyzed in the theory and methodology of teaching physics.

Works by (Zacharia, 2007; Guisasola et al., 2004; Saarelainen and Laaksonen, 2007) and others are devoted to the problem of creating the methodological system for teaching the subject "Electricity and Magnetism".

In order to define the procedure and ways of realization of the applied orientation of teaching physics it is necessary to understand the essence of this notion. Thus, "applied orientation of teaching physics it is commitment of teaching content and techniques to shaping abilities to apply the theories and laws of physics to solving tasks that appear in other brunches of knowledge, academic subjects, future professional training, using methods and techniques of physical science" (Usembayeva et al., 2014).

\section{Materials and Methods}

There are different means to implement applied orientation in teaching physics:

- Applied orientation of education content (content of basic sections of physics education that help to implement the applied direction of teaching physics, for example classes of general physics)

- Problems of practical nature (physics problem of practical nature is a problem main point of which is to show the application of physics in related sciences, to show its usage in the modern industrial management, in service sector and in everyday life)

- Cross-curriculum communications (crosscurriculum communications-is a didactic criteria which favors the systematization of an educational process and intensifies the scientific character and availability of education, increases the cognitive activity of students, improves the quality of their knowledge and gives opportunity to cultivate their scientific views and believes)

- Information and Communication Technologies (ICT) (ICT is meant as a process of finding out the complex of physics laws that describe basic mechanisms typical for the process, subject or system under investigation)

- Laboratory and practical works with the application of ICT (laboratory and practical works with the application of ICT are exercises that are solved by constructive methods using direct measuring, making graphs, computer simulation technique and constructing) 
The most effective methods of intensifying the applied orientation of teaching the subject "Electricity and Magnetism" are visual computer practical methods of teaching (laboratory works, practical classes, problem solving, execution of different exercises, work with literature (manuals, reference books, supplementary books), execution of creative tasks (design and construction of devices, models, etc.), examination paper works, etc.). All these teaching methods are based on practical activity of students performed under the supervision of a teacher with the help of ICT. An important part here is played by all types of independent work-collective, group, individual. Nowadays the part of the research method in teaching physics is becoming more significant. This method helps to solve the problem of implementation of applied orientation of teaching using ICT more efficiently and also helps to solve the problem of development of student's creative abilities.

The fulfilled analysis gave opportunity to draw a conclusion that it is necessary to create a methodological system of applied orientation of the subject "Electricity and Magnetism" using ICT for students whose major is "Physics". The primary purpose of this system is to form professional qualities of future physics teachers.

A part of our methodological system of education was the development of an academic program for the course "Electricity and Magnetism", of a work book "The applied physics course", of an electronic textbook "Electricity and Magnetism", of a study guide "Physics applied problems". There was also used an applied oriented integrated program system of a sheet-oriented modelling of analog and digital radio electronic devices Electronics Workbench and a laboratory facility "Open physics". It was all made to solve the following problems:

- To bring the educational methods and solving of problems on the subject "Electricity and Magnetism" closer to the methods used in everyday life

- To enrich a cross-curriculum knowledge of students

- To reveal the peculiarities of applied aspects of the subject using ICT

Our methodological system was developed in order to solve the following tasks:

- To form principles of student's scientific outlook, to help students understand the integral part of the subject "Electricity and Magnetism" in other subjects

- To broaden the potential of applied orientation of teaching physics, i.e., to support students in understanding the theory in combination with its applied aspects

- To develop the research abilities of students by using ICT tools in laboratory works on the subject "Electricity and Magnetism"
- To teach students how to solve problems of applied nature on the subject "Electricity and Magnetism" using ICT

- To generate the students' desire for constant replenishing and renewing of knowledge, to develop their ability for creative knowledge application in their activity, ability to understand the trends of the modern society development and the ability to use ICT in everyday life

In order to confirm our hypothesis we have conducted an experimental test on the subject of the research in 2012-2013, 2013-2014 and 2014-2015 academic years. The experiment engaged the students studying at a full-time course of natural science faculty (specialties 5B011000, 5B060400-"Physics") of Physics Department of Khoja Ahmet Yassawe International Kazakh-Turkish University, students studying at Informatics Department in Moscow Municipal Pedagogical University and in Kyzyl-Orda State University named after Korkyt. Pedagogical experiment included three stages of a particular character: The first stage was determinative, the second stage was searching and the third one was teaching (empirical and pedagogical). Experimental Group (EG) and Control Group (CG) were created in order to conduct the experiment. Before the experiment students in the control groups had better academic performance than students in the experimental groups. Total number of participating students is 76, including 38 in CG and 38 in EG.

The objectives of this empirical and pedagogical experiment are:

- To define the level and the potential of teaching the subject "Electricity and Magnetism" in universities

- To find out how the usage of ICT in methodological system of teaching the subject "Electricity and Magnetism" influences the level of applied orientation

- To study the possibility to intensify the applied orientation of teaching the subject "Electricity and Magnetism" using ICT and to set principal directions for solving this problem

- To prove that methodological system of teaching the subject "Electricity and Magnetism" using ICT is efficient for intensification of applied orientation of students

Primary tasks set for the determinative stage of the experimental work (2012-2013): To get acquainted and to analyze the process of teaching the subject "Electricity and Magnetism" to future physics teachers, to determine the intensity of usage ICT in teaching the subject, to defin student's attitude towards tasks of applied character, to specify the level of their ability to apply knowledge of physics to solve different problems. 
During the determinative experiment different methods were used: We analyzed methodological literature on psychological pedagogics and on physics, thesis researches, "Electricity and Magnetism" course programs in universities; we studied documents concerning credit systems of universities; we interviewed students and teaches. We also defined ICT favoring the intensification of applied orientation of teaching the subject "Electricity and Magnetism". This helped to determine some advantages of teaching the subject using ICT.

Results of the determinative experiment formed the basis for the hypothesis of our research and for finding ways to intensify the applied orientation of teaching the subject "Electricity and Magnetism" using ICT. This stage also included a creation of didactic materials used at tests aimed at solving physics problems, at laboratory works of applied nature using ICT that gave opportunity to determine the level of received knowledge.

The subject, aim, tasks, hypothesis and scientific apparatus of the research were determined at this stage.

The second stage-the searching one, was conducted in 2013-2014. Primary objective of this stage is the adjustment (detailing) of applied orientation method of teaching the subject "Electricity and Magnetism" with the help of ICT and revealing the difficulties that occur while teaching the subject. A methodological system of applied orientation of teaching this subject using ICT was also created and introduced to the educational process.

The primary task of the searching experiment was to evaluate the efficiency of teaching students provided that experimental groups had been taught theoretical, practical and laboratory classes in an experimental way and control groups had the same classes in a classical way. Students of experimental group had been taught classes according to the applied orientation of teaching the subject "Electricity and Magnetism" using ICT. Students of control groups had a regular course that follows classical pedagogical methods of teaching.

The intelligence level of students is similar in both groups; it was proved by earlier researches. Time period of the research corresponds to the time of the subject provided by a curriculum.

The third stage-teaching (empirical and pedagogical) was conducted in 2014-2015. This stage included the pedagogical experiment itself. During the first class students were instructed about the way the material will be studied, they were introduced to the plan of theoretical, practical and laboratory classes and to the way the regular and final testing will be performed.

The authors have made an electronic textbook that includes 20 practical tasks and 15 animations illustrating different phenomena relating to "Electricity and Magnetism" course. Exercises of applied nature with employment of ICT tools are of primary importance at the practical classes of the training system. For example, during the classes on the subject "Electric Field Intensity" students were offered to solve such problems as: Two point charges interact according to Coulomb law with the force $1 \mathrm{H}$. Define Coulomb force of interaction if the distance between them has increased in two times.

Students used our electronic textbook "Electricity and Magnetism" to determine Coulomb force of electric field intensity. Such tasks help students to see a direct interconnection between studying material and its practical application and employment of ICT tools.

At laboratory classes students can use integrated program systems of technical self-modelling of analog and digital radioelectronic devices (Micro-Cap V, DesignLab 8.0, Aplac 7.0, System View 1.9, Circuit Maker 6.0, Electronics Workbench), effectively computerizing laborious calculating transformations which focus student's attention on solving substantive tasks. Electronics Workbench is easy to understand and to use. Students need to set up a circuit and to connect monitoring instruments and then they can begin to study processes of electric circuits by pressing a virtual switch.

For example, a laboratory work "Composite electric circuit with resistors" includes the following problems for students: To apply Kirchhoff's laws, to understand superposition principle, to apply the equivalent source technique.

ICT helps to implement the visualization principle (a process and the result visualization) in a comprehensible and effective way. A computer can generate graphs, charts and gives opportunity to recreate the real atmosphere.

Factors of understanding the educational material at different levels that were set by purpose of education were assessed according to the methodology described by (Bespalko, 1995). These factors classify how good students have understood the material and how efficiently they can apply it. Knowledge and skills could be represented as four consequent levels of learning $(\varphi)$ or as an ability to solve different tasks that demonstrate how much experience students gain while studying the subject "Electricity and Magnetism":

- $\quad 1$ st level $\left(\varphi_{1}\right)$-ability to identify objects, properties and processes of this sphere at the repeated visualization of information given earlier

- $\quad$ 2nd level $\left(\varphi_{2}\right)$-ability to repeat (ability to reproduce by oneself from memory or using some algorithm)

- 3rd level $\left(\varphi_{3}\right)$-heuristic (individual reproductive activity, fulfilled by one's own algorithm or by typical algorithm that was modified during the activity)

- 4th level $\left(\varphi_{4}\right)$-creative (creative activity, that generate entirely new information)

In order to define the degree of understanding the educational material at every level we have created proper examination works that help to assess the ability 
to solve physics problems, to conduct laboratory works using ICT. These examination works included tasks and patterns, i.e., models of complete and correct actions. A pattern helps to determine number of fundamental actions that result in solving the task.

\section{Results}

According to the modern scientific didactics, if the understanding coefficient is $\mathrm{K} \geq 0.7$ then education process could be considered complete, because student is able to improve his/her knowledge by self-studying during his/her further activity. If the understanding coefficient is $\mathrm{K} \square 0.7$ then student has unstable results at repetitive inspections, he/she makes systematic mistakes during his/her further activity and is unable to correct them without assistance.

The understanding coefficient is defined by the formula:

$$
K=\frac{n}{N}
$$

where, n-is number of points that the test subject has gained and $\mathrm{N}$-is a maximum number of points. Universities of the Republic of Kazakhstan have the following distribution of points:

- If $0.9 \leq K \leq 1$ then mark is $90-100$ points

- If $0.8 \leq K \leq 0.9$ then mark is $75-89$ points

- If $0.7 \leq \mathrm{K} \leq 8$ then mark is $50-74$ points

- If $0.6 \leq \mathrm{K} \leq 0.7$ then mark is $0-49$ points

When the whole group of test subjects has completed the task then the difficulty level is defined. Four difficulty levels are accepted in pedagogical practice: $0,1,2,3$.

If a group of test subjects has a sum of points that is equal to maximum at this task then the difficulty level is 0 and the understanding coefficient (of the group) is close to 1 . If the understanding coefficient is more than 0.9 then the difficulty level is 0 , if the understanding coefficient is from 0.8 to 0.9 then the difficulty level is 1 (low), 0.7-0.8 then the difficulty level is 2 (middle), below 0.7 then the difficulty level is 3 .

At the 2nd and 3rd difficulty levels the correction of students' knowledge of this subject is required at the further classes.

Results of examination works of applied nature that include solving physics problems and conduction of laboratory works using ICT are represented in Table 1 according to every level of understanding the material in control and experimental groups.

These proportions were combined in a diagram (Fig. 1) to make the results more explicit.

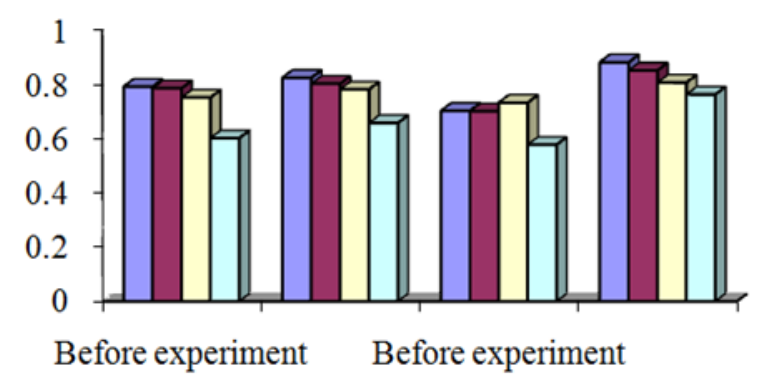

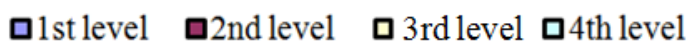

Fig. 1. Diagram of indexes of understanding the applied material on the subject "Electricity and magnetism" using ICT

Table 1. Coefficient of understanding the material in control and experimental groups

\begin{tabular}{|c|c|c|c|c|}
\hline \multirow{3}{*}{$\begin{array}{l}\text { Levels of } \\
\text { material } \\
\text { understanding } \\
(\varphi)\end{array}$} & \multicolumn{4}{|c|}{ Coefficient of material understanding (K) } \\
\hline & \multicolumn{2}{|c|}{ Control group } & \multicolumn{2}{|c|}{ Experimental group } \\
\hline & $*$ & $* *$ & $*$ & $* *$ \\
\hline 1st level $\varphi_{1}$ & 0.792 & 0.825 & 0.703 & 0.882 \\
\hline 2nd level $\varphi_{2}$ & 0.786 & 0.803 & 0.701 & 0.852 \\
\hline 3rd level $\varphi_{3}$ & 0.752 & 0.782 & 0.733 & 0.807 \\
\hline 4th level $\varphi_{4}$ & 0.602 & 0.658 & 0.578 & 0.763 \\
\hline
\end{tabular}

*Before the experiment

**After the experiment

Index of the material quality-stability. The knowledge stability factor shows for how long the images of the learned activity are kept in mind from the beginning of study up to the moment of their presentation with the quality indexes $(\varphi)$. Such definition of the stability factor limits its use very much, because retaining of the material is not the main task of the education. The only reason of getting the knowledge is their application, i.e., their applied orientation. Study of the knowledge stability in time is hindered by the possibility of the detailed control of transitional (between the two checks) examples of knowledge application (right after the education and at the moment of stability test).

The level of knowledge stability is determined according to the following method of stability evaluation. The gradual loss of experience could be approximated by a straight line (Fig. 2), the knowledge stability is measured in hours, weeks, months and determined by the following formula:

$$
T_{P}=\frac{T_{u} * j_{k}}{j_{k}-j_{u}}
$$

Where:

$j_{k}=$ An assessment (for example, on ten-point scale) at the termination of the study

$j_{u}=$ An assessment (on the same scale) at the delayed check $T_{u}=$ The time that defines the span between $j_{u}$ and $j_{k}$ 


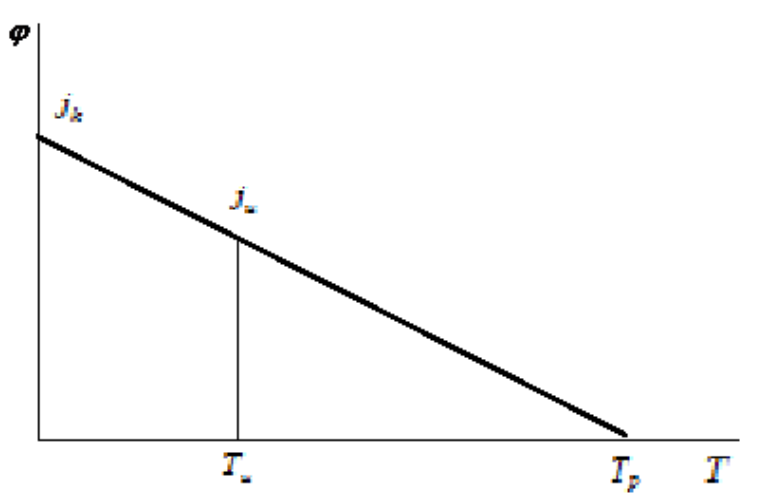

Fig. 2. The knowledge stability

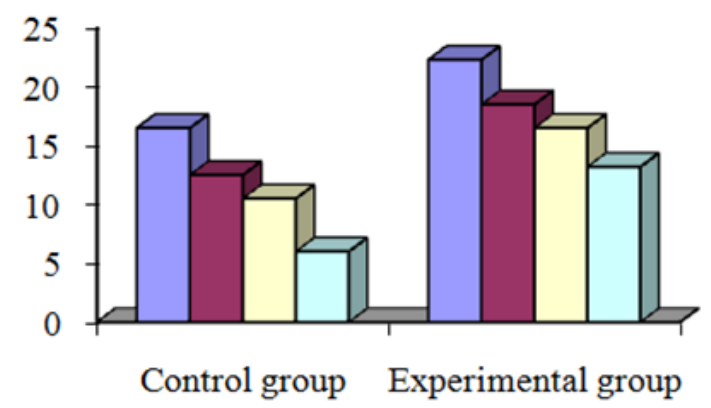

$\square$ 1st level $\square$ 2nd level $\square$ 3rdlevel $\square$ 4th level

Fig. 3. Proportion of knowledge stability coefficients

Table 2. Coefficient of the knowledge stability in control and experimental groups

\begin{tabular}{lll}
\hline & Stability factor $(T)$ & \\
Levels of material & - & \\
understanding $(\varphi)$ & Control group & Experimental group \\
\hline 1st level $\varphi_{1}$ & 16.5 & 22.3 \\
2nd level $\varphi_{2}$ & 12.5 & 18.5 \\
3rd level $\varphi_{3}$ & 10.5 & 16.5 \\
4th level $\varphi_{4}$ & 6.0 & 13.2 \\
\hline
\end{tabular}

The stability factor identification was conducted with the participation of the same students but 6 months after they have finished studying the subjects. Students were to held tests that would determine the final knowledge after every level of the material understanding. Afterwards these results were compared to the data received before. The analysis of the experimental results is given in Table 2 and Fig. 3.

According to Table 2 and Fig. 4 students of experimental groups have higher level of knowledge stability than students of control groups.

\section{Discussion}

According to the analysis of the results students who studied in experimental group have better results at examination tests that defined level of understanding than students who studied in control groups.

Results of experimental check of efficiency of the offered procedure aimed at intensification of applied orientation of the course "Electricity and Magnetism" using ICT shows that:

- The given methodological system aimed at intensification of applied orientation of teaching the subject "Electricity and Magnetism" using ICT develops applicative knowledge and skills of students

- Electronic textbook "Electricity and Magnetism" gives students a visualization of interconnection between theory and practice of the course (that is of primary importance for students) and helps to appreciate significant advantages of using ICT for solving physical and professional tasks

- While performing tasks of applied nature students gain an experience of a research work and of planning. This is an important experience for a future physics teacher

Thus, the results of the pedagogical experiment have verified our hypothesis about beneficial influence of the offered method of organization and implementation of educational process on improvement of quality of applicative knowledge and skills of students and also on their interest in studying physics. Application of acquired knowledge in solving practical tasks of a research nature encourages students and enhances their cognitive activity; as a result the course "Electricity and Magnetism" is understood completely.

\section{Conclusion}

Theoretical and experimental research on the problem of intensification of applied orientation of teaching the subject "Electricity and Magnetism" using ICT has verified the proposed hypothesis and helped to solve all assigned tasks.

Primary results of this thesis research are following.

According to the results of theoretical analysis there are not enough researches conducted in pedagogy and psychology that study the applied orientation of the subject "Electricity and Magnetism" using ICT.

Definition of psychological-pedagogical and didactic aspects of processes of knowledge acquisition that encourage the development of research abilities and professional skills of students.

During the research we have:

- Formed scientific and methodological principles of applied orientation of teaching the subject "Electricity and Magnetism" using ICT

- Made a set of applied problems using ICT 
- Worked out a system of practical and laboratory classes aimed at the improvement of applied skills and abilities

There was created an electronic textbook "Electricity and Magnetism" that form the applied orientation of teaching the subject "Electricity and Magnetism".

Experimental test of the developed procedure of crating the applied orientation of teaching the subject "Electricity and Magnetism" using ICT has confirmed that it is efficient. It was established that this procedure increases the interest in physics, helps to understand it better, improves the quality of knowledge, has a beneficial impact on the process of knowledge acquisition and encourages the application of knowledge for solving applied problems in different brunches of science.

\section{Acknowledgement}

We thank Esen Bidaybekov, professor for assistance with methodology and Kamalbek Berkimbaev, professor of H.A. Yassawe International Kazakh-Turkish University for comments that greatly improved the manuscript.

\section{Funding Information}

This work was supported and funded by the Ministry of Education and Science of the Republic of Kazakhstan and H.A. Yassawe International Kazakh-Turkish University.

\section{Author's Contributions}

Indira Usembayeva: Developed the plan of the research and carried out the study, data collection of the study sample, analysis and writing of the manuscript.

Sherzod Ramankulov and Bayan Ualikhanova: Designed and performed experiments.

Dinara Berdi and Gulnar Saparbekova: Participated in the results analysis, contributed to the drafting of the article and provided critical reviewing for significant intellectual content.

\section{Ethics}

This article is original and contains unpublished material. The corresponding author confirms that all of the other authors have read and approved the manuscript and there are no ethical issues involved.

\section{References}

Berkimbaev, K.M., A.K. Sarybayeva, G.K. Ormanova, I.B. Usembaeva and S. Zh. Ramankulov, 2013. To the question of the use of electronic educational resources for preparation of future physics teachers. Life Sci. J., 10: 105-108.
Bespalko, V.P., 1995. Pedagogy and advanced learning technologies.

Betcher, C. and M. Lee, 2009. The Interactive Whiteboard Revolution: Teaching with IWBs. 1st Edn., Aust Council for Ed Research, Camberwell, Vic., ISBN-10: 0864318170, pp: 154.

Bodur, E., 2006. The impact of constructivist approach on student's success in computer based physics education. Social Sciences Institute, Sakarya University.

DeWitt, D. and S. Siraj, 2010. Learners perceptions of technology for design of a collaborative mLearning module. World J. Educ. Technol., 2: 169-185.

Fishbane, P., S. Gasiorowicz and S. Thornton, 1996. Physics for Scientists and Engineers. New Jersey, Prentice Hall.

Ghoorchian, N., 2003. ICT in Education. 3rd Edn., Farashenakht Andisheh, Sousa, Tehran.

Guisasola, J., J. Almudi and J. Zubimendi, 2004. Difficulties in learning the introductory magnetic field theory in the first years of university. Sci. Educ., 88: 443-464. DOI: 10.1002/sce.10119

Judson, E., 2006. How teachers integrate technology and their beliefs about learning: Is there a connection? J. Comput. Teacher Educ., 14: 581-597.

Khan, S., 2011. New pedagogies on teaching science with computer simulations. J. Sci. Educ. Technol., 20: 215-232. DOI: $10.1007 / \mathrm{s} 10956-010-9247-2$

Larson, L., 2003. A descriptive study of technology integration and faculty professional development in one higher education institution. PhD Thesis, Pepperdine University.

Newhouse, P., 2003. The impact of ICT on learning and teaching. Western Australian Department of Education.

Richards, C., 2004. From old to new learning: Global imperatives, exemplary Asian dilemmas and ICT as a key to cultural change in education. Globalisation, Societ. Educ., 2: 337-353.

DOI: $10.1080 / 1476772042000252470$

Saarelainen, M. and A. Laaksonen, 2007. Students' initial knowledge of electric and magnetic fields-More profound explanations and reasoning models for undesired conceptions. Eur. J. Phys,. 28: 51-51. DOI: $10.1088 / 0143-0807 / 28 / 1 / 006$

Sousa, H., 2006. Information technologies, social change and the future the case of online journalism in Portugal. Eur. J. Commun., 21: 373-387. DOI: $10.1177 / 0267323106066656$

Steinberg, R., G. Oberem and L. McDermott, 1996. Development of a computer-based tutorial on the photoelectric effect. Am. J. Phys., 11: 1370-1379. DOI: $10.1119 / 1.18360$

Thwaites, D., R. Franich, M. Carolan, A. Fielding and M. House et al., 2014. Engineering and physical sciences in medicine conference 2013 pan pacific hotel, Perth, Australia, 3-7 November 2013 Oral presentation abstracts. Aus. Phys. Eng. Sci. Med., 37:153-269. DOI: 10.1007/s13246-014-0248-y 
Toki, E. and J. Pange, 2013. Social learning theories as tools for learning in an ICT educational system. Online J. New Horizons Educ., 3: 53-55.

Usembayeva, I., A. Bahtibayev, K. Berkimbayev and A. Saribaeva, 2014. Electronic resources in physics as a means of formation applied orientation of students. Procedia-Social Behavioral Sci., 116: 4310-4314. DOI: $10.1016 /$ j.sbspro.2014.01.938
Wieman, C., K. Perkins and W. Adams, 2008. Oersted medal lecture 2007: Interactive simulations for teaching physics: what works, what doesn't and why. Am. J. Phys., 76: 393-399.

DOI: $10.1119 / 1.2815365$

Zacharia, Z., 2007. Comparing and combining real and virtual experimentation: An effort to enhance students' conceptual understanding of electric circuits. J. Comput. Assisted Learn., 23: 120-132. DOI: $10.1111 /$ j.1365-2729.2006.00215.x 